\title{
Examining Misaligned Incentives for Payers and Manufacturers in Value-Based Pharmaceutical Contracts
}

\author{
Joseph T. Kannarkat, BSc; Chester B. Good, MD, MPH; Erin Kelly, MBA; and Natasha Parekh, MD, MS
}

\section{SUMMARY}

Value-based pharmaceutical contracts (VBPCs) are performance-based reimbursement agreements between health care payers and pharmaceutical manufacturers in which the price, quantity, or nature of reimbursement is tied to value-based outcomes. As value-based payment models have permeated through much of the health care payment landscape via reimbursement to payers and providers, VBPCs offer opportunities for manufacturers to similarly engage in performance-based models.

This article compares 2 VBPC schemes: "pay-for-failure" schemes, in which manufacturers offer rebates or discounts to payers for treatment failure, and "pay-for-success" schemes, in which manufacturers offer rebates or discounts to payers for treatment success. Each method has its own short-term and long-term trade-offs, and both lead to some degree of misaligned incentives between payers and manufacturers. These incentive differences have important downstream effects, influencing patient selection, provision of wraparound services, and nature of reimbursements. This analysis contrasts potential benefits and disadvantages for each of these approaches and offers potential solutions to address misalignment. For example, although pay-for-success models may be more aligned between payers and manufacturers, pay-for-failure contracts can be innovative and effective in controlling costs and/or improving outcomes. To illustrate, VBPCs aimed to reduce costs could incorporate total cost of care reduction as a value-based outcome.

The authors encourage payers and manufacturers to consider a blended alternative where pay-for-failure and pay-for-success outcomes could be incorporated as VBPC outcomes. Since little is known about the effect of each scheme on outcomes, further research on VBPCs is necessary to fully understand how differing incentives ultimately affect clinical outcomes and costs.

J Manag Care Spec Pharm. 2020;26(1):63-66

Copyright ( 2020 , Academy of Managed Care Pharmacy. All rights reserved.

$\mathrm{V}$ alue-based pharmaceutical contracts (VBPCs) are performance-based reimbursement agreements typically between health care payers and medical product manufacturers in which the price, quantity, or nature of reimbursement are tied to clinical, intermediate, or economic endpoints. ${ }^{1,2}$ Since value-based payment models have permeated through much of the health care payment landscape via reimbursement to payers and providers, VBPCs offer opportunities for manufacturers to similarly engage in performancebased models. ${ }^{1}$ VBPCs are a potential way to address escalating costs and uncertain real-world effectiveness of medications. Furthermore, they can improve patient access to novel health care technologies. VBPCs have grown dramatically since 1997, with more than half of publicly disclosed VPBCs developed after 2015..$^{2-4}$
These contracts, however, pose challenges. Factors affecting feasibility of VBPCs include meaningful outcome selection, transactional costs, administrative burden, limitations in data collection, agreement on contract details, determination of drug prices and associated rebates, and trust issues between payers and manufacturers. A particularly underreported challenge of VBPCs that does not exist in payer-provider valuebased arrangements is the potential misalignment of incentives between payers and manufacturers. In payer-provider valuebased payment models, where payers reimburse providers for better quality, incentives are more aligned towards complementary goals. When patient outcomes improve, providers directly benefit via value-based reimbursements, while payers benefit from decreased downstream utilization costs, as well as other desired outcomes such as patient satisfaction. Furthermore, providers and payers benefit from higher performance ratings on quality measures. With VBPCs, however, misalignment is introduced between short- and long-term incentives for payers and manufacturers

We illustrate such misalignment by examining 2 VBPC approaches: "pay-for-failure" and "pay-for-success" (Table 1). Each method differs by its direction of reimbursement for targeted outcomes, which can dictate if positive or negative reward mechanisms are used to achieve outcome goals. In payfor-failure models, manufacturers reimburse payers when outcomes among users of a given drug do not meet expectations, while pay-for-success models have manufacturers reimburse payers when their respective drugs achieve favorable outcome targets. To better illustrate these contrasting approaches, consider a medication aimed at targeting type 2 diabetes. A payfor-failure contract could require a manufacturer to reimburse the payer if a patient continues to have poor diabetic control, as manifested by a persistent hemoglobin Alc greater than $9 \%$. A pay-for-success contract, on the other hand, could mandate that a manufacturer reimburse the payer if diabetes control is achieved and maintained, as evidenced by Alc levels within a predetermined target range. These approaches represent varied incentives that can lead to different behaviors for manufacturers and providers. While every payer desires improved clinical outcomes in its patient population, the rewards of a VBPC may provide health plans additional incentives to achieve those clinical outcomes. 


\begin{tabular}{|c|c|c|}
\hline & Short-Term Incentive & Long-Term Incentive \\
\hline $\begin{array}{l}\text { Traditional } \\
\text { "pay-for-failure" } \\
\text { scheme } \\
\text { (payer is } \\
\text { reimbursed for } \\
\text { medication } \\
\text { failure) }\end{array}$ & $\begin{array}{l}\text { Payer: } \\
\text { - drug failure for VBPC } \\
\text { - drug success for } \\
\text { population health } \\
\text { Manufacturer: } \\
\text { - drug success for VBPC } \\
\text { and increased market } \\
\text { share/formulary } \\
\text { design } \\
\text { - select patients who } \\
\text { might benefit from } \\
\text { drug the most }\end{array}$ & $\begin{array}{l}\text { Payer: } \\
\text { - drug success for } \\
\text { population health } \\
\text { Manufacturer: } \\
\text { - drug success for } \\
\text { increased market share/ } \\
\text { formulary design }\end{array}$ \\
\hline $\begin{array}{l}\text { Alternative } \\
\text { "pay-for-success" } \\
\text { scheme } \\
\text { (payer is } \\
\text { reimbursed for } \\
\text { medication } \\
\text { success) }\end{array}$ & $\begin{array}{l}\text { Payer: } \\
\text { - drug success for VBPC } \\
\text { and population health } \\
\text { - select patients who } \\
\text { might benefit from } \\
\text { drug the most } \\
\text { Manufacturer: } \\
\text { - drug failure for VBPC } \\
\text { - drug success for } \\
\text { increased market } \\
\text { share/formulary } \\
\text { design } \\
\end{array}$ & $\begin{array}{l}\text { Payer: } \\
\text { - drug success for } \\
\text { population health } \\
\text { Manufacturer: } \\
\text { - drug success for } \\
\text { increased market share/ } \\
\text { formulary design }\end{array}$ \\
\hline
\end{tabular}

VBPC $=$ value-based pharmaceutical contracts.

\section{Pay-for-Failure VBPCs}

Traditional pay-for-failure VBPC arrangements penalize manufacturers while rewarding payers via rebates when drugs perform poorly. ${ }^{5}$ For example, Harvard Pilgrim has developed a VBPC for the Novartis heart failure drug sacubitril/valsartan (Entresto). If the heart failure-related hospitalization rate for sacubitril/valsartan users exceeds a predetermined threshold, Novartis pays Harvard Pilgrim an undisclosed amount as a discount. ${ }^{2,6}$ These traditional pay-for-failure contracts create misaligned incentives in 2 ways: (1) payers have opposing short-term and long-term incentives for drugs to perform well clinically, and (2) incentives vary between payers and manufacturers. In the short-term, payers receive rebates for unfavorable health outcomes in their enrollees (heart failure-related hospitalizations), but this opposes the long-term benefit that payers achieve from their enrollees experiencing decreased heart failure-related hospitalizations as a result of sacubitril/ valsartan use. On the other hand, manufacturers' short- and long-term incentives are aligned: if their drug is effective, they pay fewer rebates to payers in the short term, and their respective drug can gain preferred formulary status and/or increased market share over time.

As a result, pay-for-failure contracts incentivize manufacturers to behave differently than their traditional roles in 2 ways.
First, pay-for-failure schemes ideally incentivize manufacturers to advocate for selecting patients likely to benefit from treatment (rather than a traditional manufacturer business model that solely aims to increase volume). For instance, in the Health Alliance's risedronate (Actonel) VBPC, the manufacturer reimburses the Health Alliance for health care costs resulting from fractures among risedronate users. From a patient selection perspective, this could be good or bad. If, in this case, the VBPC incentivizes the manufacturer to encourage patient selection focused on those who would be most likely to benefit from risedronate, that would be beneficial. However, the manufacturer might advocate for use of the drug in low-risk populations (i.e., those who are unlikely to experience a fracture regardless of therapy with risedronate) or to avoid use in patients at highest risk for fracture. ${ }^{2,7}$ In the latter example, those patients most likely to achieve benefit are also the population most likely to experience a fracture, and the manufacturer's incentive would be to not seek them out. Payers engaged in pay-for-failure VBPCs for risedronate, on the other hand, do not have similar incentives to avoid use of risedronate in high-risk populations, since they receive rebates for adverse outcomes. This behavior may be in contrast with general strategies that payers might use to avoid risk among their enrollees independent of VBPCs, such as limiting specialist participation in provider networks or restricting member access to expensive drugs that treat rare or catastrophic conditions.

An additional potential repercussion of pay-for-failure contracts is the manufacturer provision of wraparound services that promote medication adherence and care management around effective use of their medications. One such manufacturer-based wraparound program involved Abbvie's anti-inflammatory disease-modifying medication adalimumab (Humira). In 2010, Abbvie began a patient support program to promote medication adherence, with a goal to improve clinical outcomes, diminish preventable health care utilization, and lower disease management costs. An industry-led publication reported that adalimumab users enrolled in a patient support program for ankylosing spondylitis had a 23\% increased likelihood of controlled disease progression than adalimumab users who did not participate. ${ }^{8}$

Although manufacturer provision of wraparound services may benefit patients, there are issues of potential concern for payers. Wraparound services are traditionally a role led by providers, payers, and pharmacy benefit managers. Hence, there is a risk of unsynchronized duplicated care coordination efforts between payers and manufacturers when manufacturers provide patient support programs. Patients might be confused by the role of the manufacturer, and clinicians may not be aligned with the interventions provided. In addition, patients, payers, and providers may distrust manufacturers with a care coordination role, since this is a nontraditional purview for pharmaceutical companies. Specifically, there is concern that 
manufacturer provision of wraparound services may persuade patients to remain on high-cost drugs and hinder efforts to steer patients to lower-cost therapeutic alternatives, such as biosimilars or generics. Finally, it may be difficult for less established manufacturers to have resources to sustain these services.

\section{Pay-for-Success VBPCs}

To better address the misalignment in traditional pay-forfailure VBPCs, an alternative pay-for-success approach has been implemented in which payers receive rebates for favorable rather than poor drug performance. In this alternative scheme, a manufacturer has differing short- and long-term incentives for its drug to be successful: When a drug successfully reaches positive outcome targets, its manufacturer is penalized in the short term by paying higher rebates to the payer. In the long term, manufacturers are rewarded when their drugs are successful by creating opportunities to increase their market share via formulary design strategies that optimize access to their drugs. Payer incentives, on the other hand, are aligned in pay-for-success contracts-in the short term, payers are rewarded for beneficial clinical outcomes through outcomes-based rebates, and in the long term, they may choose to promote drugs that demonstrate real-world effectiveness via VBPCs (long-term incentive is similar for pay-for-failure arrangements).

In this scheme, payers are incentivized to optimize patients for success via wraparound programs that promote adherence and care management. Of note, similar to the mistrust that may occur when manufacturers provide wraparound services in pay-for-failure VBPCs, patients and providers may suspect that payer-based care management efforts may solely function to minimize short-term costs rather than optimize long-term clinical outcomes. In addition, this scheme also incentivizes payers, rather than manufacturers, to select patients likely to experience treatment success.

An example of a pay-for-success VBPC was implemented with Cigna and Merck for the diabetes medications sitagliptin (Januvia) and sitagliptin-metformin (Janumet). When sitagliptin and sitagliptin-metformin users experienced improvement in diabetes control as evidenced by reduction in Alc levels, and when medication adherence was demonstrated, discounts increased. ${ }^{9}$

The primary disadvantage of this alternative pay-for-success scheme is that manufacturers might be less incentivized in the short term to support wraparound programs and select patients who may succeed most, since better performance would result in higher rebates. This concern, however, is mitigated by the fact that wraparound services focused on those at risk in VBPCs may still be offered by providers, payers, and pharmacy benefits managers.

\section{Strategies to Overcome Incentive Misalignment}

Incentive misalignment is inherent in pay-for-failure and pay-for-success VBPCs, and 1 scheme may be favored over the other depending on the disease, outcomes, and contract details. For many diseases, VBPCs that reward success may be philosophically desired over pay-for-failure schemes, since payers and manufacturers stand to benefit from the success of drugs. However, in some situations pay-for-failure VBPCs are innovative, and they should be considered if incentives are aligned for payers and patients. For instance, VBPCs that offer rebates to payers when total costs of care (TCOC), which include the cost of health services and medications, are higher than anticipated are a form of pay-for-failure VBPCs. However, TCOC-based contracts are particularly innovative (especially when costs are adjusted for factors such as comorbidities and age), since for both payers and patients, lowered TCOC generally indicates better clinical outcomes. Furthermore, from the payer perspective, not receiving rebates would be preferred, since lowered TCOC would almost certainly offset any lost rebates from the VBPC that would have accrued had TCOC increased. For example, the UPMC Health Plan implemented a VBPC with Boehringer Ingelheim for the type 2 diabetes drug empagliflozin (Jardiance) that demonstrates how this metric can be used as a performance indicator for a VBPC. ${ }^{10}$ The contract stipulates that the manufacturer provides additional reimbursements if TCOC is higher among empagliflozin users compared with other type 2 diabetes drugs.

There is a dearth of literature assessing the effect of different types of VBPCs. In order to fully understand the effect of the different schemes on cost and clinical outcomes, these schemes must be studied further. Also, to rectify discordant pay-for-failure and pay-for-success concepts, we suggest further investigation into a "blended" approach to assess whether the drawbacks of both types of models could potentially be mitigated-payers and providers could consider multiple value-based outcomes in a VBPC, with some being pay-for-success and some being pay-for-failure. For instance, a VBPC for a diabetes drug could designate that payers receive rebates for improved diabetes control with Alc reduction (pay-for-success) and excess cardiovascular events (pay-for-failure). In this example, receiving rebates for Alc reduction encourages the payer to have a vested interest in the drug's success in the short and long term but misaligns the manufacturer's interests by creating an incentive for drugs to be less effective in the short term due to outcomebased reimbursements to the payer. By additionally incorporating cardiovascular events, the modified approach mitigates this misalignment by modifying the manufacturer's short-term incentive to support the reduction of cardiovascular events. The effectiveness of such a contract would have to be tested to determine which incentives manifest.

A limitation to our analysis of VBPC incentives (pay-forsuccess vs. pay-for-failure) is that we do not consider the 
magnitude of financial exposure of the manufacturer in these agreements. Because details of VBPCs are typically confidential, it is unknown whether there is truly enough "skin in the game" for manufacturers to be adversely incentivized in the examples previously mentioned. While we acknowledge this limitation, we posit that as VBPCs become increasingly viewed as a mechanism for improving the value of pharmaceuticals, careful consideration of the underlying philosophy of these contracts is important.

\section{Conclusions}

There are various ways to develop incentive schemes linking patient outcomes to drug performance, but short-term and long-term incentives from the manufacturer and payer should be considered in contract development. A misalignment of incentives between the payer and manufacturer may lead to conflicting desires for a successful contract. VBPCs have had a difficult time gaining traction in the pharmaceutical space; in order to optimize the success of VBPCs, research is needed on the effect of different types of VBPC schemes on cost and clinical outcomes, and payers and manufacturers must be transparent about their incentives and work collaboratively to align them.

\section{Authors}

JOSEPH T. KANNARKAT, BSc, Department of Politics and International Studies, University of Cambridge, United Kingdom. CHESTER B. GOOD, MD, MPH, and NATASHA PAREKH, MD, MS, UPMC Centers for Value-Based Pharmacy Initiatives and High-Value Health Care, UPMC Insurance Services Division, and University of Pittsburgh Division of General Internal Medicine, Pittsburgh, Pennsylvania. ERIN KELLY, MBA, UPMC Centers for Value-Based Pharmacy Initiatives and High-Value Health Care, UPMC Insurance Services Division, Pittsburgh, Pennsylvania.

AUTHOR CORRESPONDENCE: Joseph T. Kannarkat, BSc, 4625 Dillon St., Baltimore, MD 21224. Tel.: 703.609.4008;

E-mail: josephkannarkat@gmail.com

\section{DISCLOSURES}

No outside funding supported the writing of this article. Good and Kelly are employed by the UPMC Centers for Value-Based Pharmacy Initiatives and High-Value Health Care, and Parekh was employed by the UPMC Centers for Value-Based Pharmacy Initiatives and High-Value Health Care at the time of this study. The authors have no other disclosures to report.

\section{REFERENCES}

1. Carlson JJ, Sullivan SD, Garrison LP, Neumann PJ, Veenstra DL. Linking payment to health outcomes: A taxonomy and examination of performancebased reimbursement schemes between healthcare payors and manufacturers. Health Policy. 2010;96(3):179-90.

2. Yu JS, Chin L, Oh J, Farias J. Performance-based risk-sharing arrangements for pharmaceutical products in the United States: a systematic review. J Manag Care Spec Pharm. 2017;23(10):1028-40. Available at: https://www. jmcp.org/doi/10.18553/jmcp.2017.23.10.1028.

3. Mahendraratnam N, Sorenson C, Richardson E, et al. Value-based arrangements may be more prevalent than assumed. Am J Manag Care. 2019;25(2):70-76

4. Seeley E, Chimonas S, Kesselheim AS. Can outcomes-based pharmaceutical contracts reduce drug prices in the US? A mixed methods assessment. J Law Med Ethics. 2019;46(4):952-63.

5. Garrison L, Carlson J. Performance-based risk-sharing arrangements for drugs and other medical products [slide presentation]. University of Washington. Available at: https://depts.washington.edu/pbrs/PBRS_slides. pdf. Accessed November 26, 2019.

6. Teichert E. Harvard Pilgrim scores discounts on Novartis, Lilly drugs. Modern Healthcare. June 28, 2016. Available at: https://www.modernhealthcare.com/article/20160628/NEWS/160629889/harvard-pilgrim-scoresdiscounts-on-novartis-lilly-drugs. Accessed November 26, 2019

7. Pollack A. Drug deals tie prices to how well patients do. The New York Times. April 22, 2009. Available at: https://www.nytimes.com/2009/04/23/ business/23cigna.html. Accessed November 26, 2019.

8. Bessette L, Lebovic G, Millson B, et al. Impact of the adalimumab patient support program on clinical outcomes in ankylosing spondylitis: results from the companion study. Rheumatol Ther. 2018;5(1):75-85.

9. CIGNA and Merck sign performance-based contract. Business Wire. April 23, 2009. Available at: https://www.businesswire.com/news/ home/20090423005503/en/CIGNA-Merck-Sign-Performance-BasedContract. Accessed November 26, 2019

10. Pferdehirt G. UPMC Health Plan and Boehringer Ingelheim announce innovative, value-based agreement. UPMC Health Plan. September 27, 2018. Available at: https://www.upmchealthplan.com/pdf/ReleasePdf/2018_09_27. html. Accessed November 26, 2019. 